\title{
Cervical cancer risk factors and feasibility of visual inspection with acetic acid screening in Sudan
}

This article was published in the following Dove Press journal:

International Journal of Women's Health

25 March 201I

Number of times this article has been viewed

\section{Ahmed Ibrahim' \\ Vibeke Rasch ${ }^{2}$ \\ Eero Pukkala ${ }^{3}$ \\ Arja R Aro'}

'Unit for Health Promotion Research, University of Southern Denmark, Esbjerg, Denmark; ${ }^{2}$ Department of Obstetrics and Gynecology, Odense University Hospital, Odense, Denmark; ${ }^{3}$ Institute for Statistical and Epidemiological Cancer Research, Finnish Cancer Registry, Helsinki, Finland
Correspondence: Ahmed Ibrahim Unit for Health Promotion Research, University of Southern Denmark, Niels Bohr Vej 9-10, 6700,

Esbjerg, Denmark

Tel +4565504242

Email aibrahim@health.sdu.dk
Objectives: To assess the risk factors of cervical cancer and the feasibility and acceptability of a visual inspection with acetic acid (VIA) screening method in a primary health center in Khartoum, Sudan.

Methods: A cross-sectional prospective pilot study of 100 asymptomatic women living in Khartoum State in Sudan was carried out from December 2008 to January 2009. The study was performed at the screening center in Khartoum. Six nurses and two physicians were trained by a gynecologic oncologist. The patients underwent a complete gynecological examination and filled in a questionnaire on risk factors and feasibility and acceptability. They were screened for cervical cancer by application of $3 \%-5 \%$ VIA. Women with a positive test were referred for colposcopy and treatment.

Results: Sixteen percent of screened women were tested positive. Statistically significant associations were observed between being positive with VIA test and the following variables: uterine cervix laceration (odds ratio [OR] 18.6; 95\% confidence interval [CI]: 4.64-74.8), assisted vaginal delivery (OR 13.2; 95\% CI: 2.95-54.9), parity (OR 5.78; 95\% CI: 1.41-23.7), female genital mutilation (OR 4.78; 95\% CI: 1.13-20.1), and episiotomy (OR 5.25; 95\% CI: 1.15-23.8). All these associations remained statistically significant after adjusting for age, educational level, employment, and potential confounding factors such as smoking, number of sexual partners, and use of contraceptive method. Furthermore, the VIA screening method was found to be feasible and acceptable to participants.

Conclusion: This pilot study showed that women who have uterine cervix laceration, assisted vaginal delivery, female genital mutilation, or episiotomy are at an increased risk of cervical cancer. It also showed that VIA is a feasible and acceptable cervical cancer screening method in a primary health care setting.

Keywords: cervical cancer, screening, visual inspection, acetic acid, feasibility

\section{Background}

Cervical cancer is one of the leading causes of death for middle-aged women in the developing world, yet it is almost completely preventable if precancerous lesions are identified and treated in a timely manner. ${ }^{1}$ There are many risk factors for cervical cancer, which include human papillomavirus infection, ${ }^{2,3}$ early age at first sexual intercourse, ${ }^{2,4,5}$ increased number of sexual partners, ${ }^{2,5}$ long-term use of oral contraceptives, ${ }^{6}$ smoking ${ }^{2,3,7,8}$ history of infertility, ${ }^{9}$ intrauterine device, ${ }^{9}$ high parity, ${ }^{10,11-13}$ trauma with pregnancy, ${ }^{14,15}$ low education, ${ }^{16}$ and low socioeconomic level. ${ }^{17}$ Factors reducing risk of cervical cancer include male circumcision, ${ }^{2,3,7,10,18}$ use of condoms, ${ }^{3,5}$ abstinence from sexual intercourse during menses time, and celibate status. ${ }^{19}$ 
Cervical cancer screening based on cytological examination is largely unavailable in developing countries or available only to a small, select group of women in private facilities, maternal child health sites, or family planning clinics, thereby missing the age groups at the highest risk for precancerous lesions. ${ }^{1}$ The failure of a conventional cytology-based approach to reducing cervical cancer in developing countries, particularly in Africa, can be attributed to several factors, including scarcity of trained, skilled professionals, lack of resources, and expense. ${ }^{20}$ There is interest in a new screening method using visual techniques to identify cervical cancer.

These visual techniques can be divided into two general categories. One is the simple screening method, such as visual screening by use of acetic acid (VIA), during which the cervix is visualized with the naked eye under a direct source of light, and application of a solution of 3\%-5\% acetic acid that is used as a chemical contrast agent to highlight areas of metaplastic changes. The mechanism of the VIA test is a chemical reaction between neoplasia acetic acid. When neoplastic tissue is stained with acetic acid $(3 \%-5 \%)$, it uptakes the acetic acid and changes to a whitish color (acetowhite area). If this occurs, a positive VIA test is reported, and it indicates that there is a malignant change in the aceto-white area in the cervix, which is precisely around the squamocolumnar junction, the main anatomical site where cervical malignant neoplasia develops. ${ }^{21}$

VIA has been evaluated in a number of large clinical trials and is considered to be a possible alternative to cervical cytology for primary cervical cancer screening in low-resource settings. The advantages of VIA compared with cervical cytology are that it is inexpensive, it does not require a laboratory infrastructure, and it provides an immediate result, allowing use of "screen and treat" protocols. ${ }^{22}$ The simple visual screening methods are being evaluated as an alternative to cytology in low-resource settings where screening using cervical cytology is not feasible. Multiple studies have shown VIA to have sensitivity similar to that of cervical cytology but much lower specificity for identifying women with high-grade cervical cancer lesion and squamous intraepithelial lesion. ${ }^{23}$ VIA showed a sensitivity of $79 \%$ (95\% confidence interval [CI] 73\%-85\%) and $83 \%(95 \% \mathrm{CI} 77 \%-89 \%)$, and a specificity of $85 \%(95 \%$ CI $81 \%-89 \%)$ and $84 \%(95 \% \mathrm{CI} 80 \%-88 \%)$ for CIN2+ and CIN3+, respectively. ${ }^{24}$ VIA can be easily implemented as a quick and inexpensive test in unsophisticated health care settings. Also, this method can provide the result of screening immediately, and the patient can be treated with cryotherapy at the same time.
The aim of the present study conducted among women in Khartoum State, Sudan, was to assess risk factors of cervical cancer and the feasibility and acceptability of a single-visit method for cervical cancer screening by using VIA in a primary health care setting.

\section{Material and methods}

Six nurses and two supervisors were trained on prescreening counseling, data collection and VIA screening methods in a primary health care center setting by an investigator and gynecological oncology consultant from the Radiation and Isotopes Center in Khartoum. A campaign to raise public awareness about cervical cancer among the local women was performed. Posters and pamphlets were distributed to women in public places at primary health centers, shopping centers, and transport centers. A program about cervical cancer and VIA screening methods was presented by a gynecological oncologist and investigator at the local radio broadcasting station. In addition, in the context of Friday and Sunday prayers, Imams in mosques and clerks in churches talked about cervical cancer screening and encouraged women to participate in the screening project.

House-to-house visits were used to recruit participants. During the home visits, pamphlets were distributed, and women were informed about cervical cancer and about the opportunity for prevention and treatment by early detection. Healthy nonpregnant women aged 25-50 years living in Khartoum State in Sudan who were voluntarily willing to participate in screening were included in the study. Eligible women were given an appointment for screening at the cervical cancer screening clinic, and questionnaires containing sociodemographic, obstetric, and gynecologic variables and other risks factors were filled in. At the screening clinic, a counseling session about the screening test procedures was delivered either at an individual or a group level. Written informed consent was signed by all women who had agreed to have a screening test.

The VIA test was performed by adding $5 \mathrm{~mL}$ of acetic acid (vinegar) to $95 \mathrm{~mL}$ of distal water in a sterile kidney dish to compose $5 \%$ acetic acid. Women were asked to lie on their back in a lithotomy position, in the presence of a good source of light. The external genitals were inspected and cleaned with use of gauze and normal saline, and then a sterile bivalve speculum was inserted into the vagina. The vagina wall and cervix were inspected for the presence of tumors and other diseases. Any mucus or discharge at the cervix was cleaned with the use of sterile cotton. Then, the squamocolumnar junction was determined and acetic acid was applied. VIA positive 
was defined as well-marginated, raised, opaque, aceto-white lesion at the squamocolumnar junction. ${ }^{21}$ VIA-positive women were referred to the oncology gynecologist at the Radiation and Isotopes Center for treatment. VIA-negative women were assured and asked to have the test repeated after 5 years. Women who had other diseases such as bacterial or fungal infection were also treated at the screening center. The treatment was offered free of charge.

\section{Statistical analysis}

Descriptive statistics was used to characterize participants; Chi-square, and Fischer's exact tests were used to assess differences in proportions between dichotomous outcome and explanatory variables; and the Student's $t$-test was used to assess differences in means of age. Odds ratios (ORs) were calculated to assess associations between risk factors and diagnosis of cervical cancer with use of the VIA test. Significance level was set at $P<0.05$ and CI at 95\%. All statistical analyses were performed using Stata Version 9.2 (StataCorp, College Station, TX).

\section{Results}

One hundred and fifty women aged 25-50 years were invited to participate in the cervical cancer screening project, and 100 women attended the screening clinic (response rate of 67\%). Table 1 shows the characteristics of the subjects. The mean age was 35 years, $36 \%$ had no education, and 33\% were employed. Sixty-four percent of the participating women had had genital mutilation. Sixty percent were parous, $80 \%$ of them had spontaneous vaginal delivery, $62 \%$ were episiotomized, and $12 \%$ had laceration. Only $30 \%$ of screened women used contraceptive methods, but $97 \%$ practised in the lower part of the body. Of the male partners, $98 \%$ were circumcised.

Table 2 describes the association between risk factors and cervical cancer diagnosis with the use of VIA. A highly statistically significant association was observed between cervical cancer and uterine cervix laceration (OR 18.6, 95\% CI: 4.64-74.8). Assisted vaginal delivery was also strongly related to cervical cancer (OR 13.2; 95\% CI: 2.95-54.9).

Risk of cervical cancer was significantly higher among parous than among nulliparous women (OR 5.78; 95\% CI: 1.41-23.7). Moreover, this study showed that there was a statistically significant association between a positive VIA result and female genital mutilation (OR 4.78; 95\% CI: 1.13-20.1). Furthermore, the result showed a statistically significant association between episiotomy and a positive VIA results (OR 5.25; 95\% CI: 1.15-23.8). All these statistically
Table I Characteristics of the participants in cervical cancer screening with the visual inspection with acetic acid (VIA) method in Khartoum State, Sudan

\begin{tabular}{|c|c|c|c|}
\hline \multirow[t]{3}{*}{ Characteristics } & \multirow{2}{*}{$\begin{array}{l}\text { Total } \\
(n=100)\end{array}$} & \multicolumn{2}{|l|}{ VIA test } \\
\hline & & $\begin{array}{l}\text { Negative } \\
(n=84)\end{array}$ & $\begin{array}{l}\text { Positive } \\
(n=16)\end{array}$ \\
\hline & $\mathbf{N}(\%)$ & $\mathbf{N}(\%)$ & $\mathbf{N}(\%)$ \\
\hline \multicolumn{4}{|l|}{$\overline{\text { Age }}$} \\
\hline Mean age & 37.2 & 34.1 & 40.3 \\
\hline$\leq 35$ years & $52(52)$ & $45(54)$ & $7(44)$ \\
\hline$\geq 36$ years & $48(48)$ & $39(46)$ & $9(56)$ \\
\hline \multicolumn{4}{|l|}{ Education } \\
\hline Yes & $36(36)$ & $32(38.1)$ & $4(25)$ \\
\hline No & $64(64)$ & $52(6 \mid .9)$ & $12(75)$ \\
\hline \multicolumn{4}{|l|}{ Employment } \\
\hline Yes & $33(33)$ & $29(34.5)$ & $4(25)$ \\
\hline No & $67(67)$ & $55(65.5)$ & $12(75)$ \\
\hline \multicolumn{4}{|l|}{ Smoking } \\
\hline Yes & $4(4)$ & $2(2.4)$ & $2(12.5)$ \\
\hline No & $96(96)$ & $82(97.6)$ & $14(87.5)$ \\
\hline \multicolumn{4}{|c|}{ Female genital mutilation } \\
\hline Yes & $90(90)$ & $76(90.5)$ & $14(87.5)$ \\
\hline No & $10(10)$ & $8(9.5)$ & $2(12.5)$ \\
\hline \multicolumn{4}{|c|}{ Male partner circumcision } \\
\hline Yes & $98(98)$ & $83(98.8)$ & $15(93.7)$ \\
\hline No & $2(2)$ & $\mathrm{I}(\mathrm{I} .2)$ & I (6.3) \\
\hline \multicolumn{4}{|l|}{ Contraception } \\
\hline Yes & $30(30)$ & $27(32.1)$ & $3(18.8)$ \\
\hline No & $70(70)$ & 57 (67.9) & $13(81.2)$ \\
\hline \multicolumn{4}{|c|}{ Practice of duhan lower part of the body } \\
\hline Yes & $97(97)$ & $82(8 \mid .5)$ & $15(93.7)$ \\
\hline No & $3(3)$ & $2(2.5)$ & I (6.3) \\
\hline \multicolumn{4}{|l|}{ Parity } \\
\hline Nulliparous & $40(40)$ & $38(45.2)$ & $2(12.5)$ \\
\hline Parous & $60(60)$ & $46(54.8)$ & $14(87.5)$ \\
\hline \multicolumn{4}{|c|}{ Vaginal delivery (out of parous $n=60$ ) } \\
\hline Spontaneous & $48(75)$ & $42(91.3)$ & $6(4 I .9)$ \\
\hline Assisted & $12(25)$ & $4(8.7)$ & $8(57.1)$ \\
\hline \multicolumn{4}{|c|}{ Episiotomy (out of parous $n=60$ ) } \\
\hline Yes & $37(6 \mid .7)$ & $24(28.2)$ & $12(9.8)$ \\
\hline No & $23(38.3)$ & $21(17.8)$ & $2(6.2)$ \\
\hline \multicolumn{4}{|c|}{ Uterine cervix laceration } \\
\hline Yes & $7(7)$ & $2(2.4)$ & $5(3 \mid .3)$ \\
\hline No & $93(93)$ & $82(97.6)$ & II (68.7) \\
\hline
\end{tabular}

significant associations remained after adjusting for other factors, including age, educational level, and employment, and potential confounding factors, such as smoking, number of sexual partners, and use of contraceptive methods. No statistically significant findings were found for male partner circumcision, use of contraception method, or use of cosmetic smoking in the lower part of the body.

This study revealed a high proportion of accessibility to the screening method. About $98 \%$ of screened women were satisfied with their decision to be screened. A total of $81.6 \%$ 
Table 2 Associations between risk factors and cervical cancer with use of the visual inspection with acetic acid (VIA) screening method in Khartoum State, Sudan $(n=100)$

\begin{tabular}{|c|c|c|c|c|c|}
\hline Risk factor & \% VIA (positive) & $\%$ VIA (negative) & Odds ratio & $\begin{array}{l}95 \% \text { confidence } \\
\text { interval }\end{array}$ & $P$ value \\
\hline Uterine cervix laceration & 71.4 & I I.8 & 18.6 & $4.64-74.8$ & 0.001 \\
\hline Assisted vaginal delivery & 66.7 & 12.5 & 13.2 & $2.95-58.9$ & 0.003 \\
\hline Parity & 23.3 & 5 & 5.78 & $1.4 \mathrm{I}-23.7$ & 0.02 \\
\hline Female genital mutilation & 21.9 & 5.5 & 4.78 & $1.13-20.1$ & 0.04 \\
\hline Episiotomy & 32.4 & 8.7 & 5.25 & $1.15-23.8$ & 0.05 \\
\hline Male partner circumcision & 18.1 & 50.0 & 0.18 & $0.01-2.29$ & 0.3 \\
\hline Use of contraception method & 10 & 18.5 & 0.48 & $0.13-1.83$ & 0.3 \\
\hline Use of cosmetic smoking in lower part of body & 18.3 & 33.3 & 0.53 & $0.03-3.96$ & 0.4 \\
\hline
\end{tabular}

of participants stated that the visit to the screening clinic took less than 45 minutes (Table 3). Treatment was postponed due to a lack of resources for two patients $(12.5 \%)$.

\section{Discussion}

In this pilot study of 100 women in Khartoum State, Sudan, $16 \%$ of women had a positive VIA result. The major risk factors were uterine cervix laceration, assisted vaginal delivery, female genital mutilation, and episiotomy. Screening was feasible and acceptable, both in terms of participation rate and the experience of women. The slow natural development of cervical cancer is crucial to a screening method that identifies dysplasia and prevents its progression to invasive carcinoma. The cervical cancer prevalence of $16 \%$

Table 3 Acceptability and feasibility of cervical cancer with the use of the visual inspection with acetic acid (VIA) screening method in Khartoum State, Sudan $\left(n=98^{a}\right)$

\begin{tabular}{|c|c|c|c|}
\hline Outcome variable & Yes (\%) & No (\%) & $P$ value \\
\hline $\begin{array}{l}\text { Satisfied with the decision } \\
\text { to be screened }\end{array}$ & $96(97.7)$ & $2(2.3)$ & 0.0001 \\
\hline $\begin{array}{l}\text { Visit to the screening clinic } \\
\text { took less than } 45 \text { minutes }\end{array}$ & $85(86.7)$ & $13(13.7)$ & 0.0001 \\
\hline $\begin{array}{l}\text { Counseling provided enough } \\
\text { information about screening }\end{array}$ & $89(90.8)$ & $9(9.2)$ & 0.0001 \\
\hline $\begin{array}{l}\text { Waiting time before screening } \\
\text { was less than } 20 \text { minutes }\end{array}$ & $82(83.7)$ & $16(16.3)$ & 0.0001 \\
\hline $\begin{array}{l}\text { Screening test procedure was } \\
\text { less than } 25 \text { minutes }\end{array}$ & $79(80.6)$ & $19(19.4)$ & 0.0001 \\
\hline $\begin{array}{l}\text { Counseling provided enough } \\
\text { information about screening }\end{array}$ & $89(90.8)$ & $9(9.2)$ & 0.0001 \\
\hline $\begin{array}{l}\text { Test experience was better } \\
\text { than expected }\end{array}$ & $87(88.8)$ & $12(12.4)$ & 0.0001 \\
\hline $\begin{array}{l}\text { Was informed immediately about } \\
\text { the result after the screening test }\end{array}$ & $95(96.9)$ & $3(3.1)$ & 0.0001 \\
\hline $\begin{array}{l}\text { Recommended screening } \\
\text { test to other women }\end{array}$ & 91 (92.9) & $7(7.1)$ & 0.0001 \\
\hline $\begin{array}{l}\text { Treatment was offered } \\
\text { free of charge }\end{array}$ & $12(87.5)$ & $2(12.5)$ & 0.0001 \\
\hline
\end{tabular}

Note: a Two women did not reply to this part of questionnaire, so they were excluded. was the same as in Nigeria; higher than in Kenya, Ghana (14\%), and Latin America (12\%); and lower than in South Africa and Zimbabwe, where the VIA test was positive in $26 \%$ of the study population. ${ }^{25-30}$

The results strongly suggest that incidents causing trauma to the uterine cervix are risk factors for cervical cancer in Khartoum State. This was true for women with uterine cervix laceration, genital mutilation, women who delivered vaginally, women who had had an episiotomy, women who had undergone assisted vaginal delivery, and parous women.

Also, earlier episiotomy has been reported as a site for implantation and recurrence of cervical cancer in women who had cervical cancer during pregnancy and delivered vaginally. ${ }^{31-36}$ It has been reported that metaplastic changes are also influenced by the trauma and repair experienced during delivery, and increased risk of cervical carcinoma has been identified in women who are highly parous. ${ }^{37,38}$ The results of this study revealed that uneducated and unemployed women had high risk of cervical cancer, which are consistent with previous studies that show that cervical cancer is more prevalent in low-educated and low socioeconomic status populations. ${ }^{16,17}$ Factors such as cosmetic smoking of the lower body and partner circumcision are very common practices among the sample, which made it impossible to study them as risk factors for cervical cancer. This remains to be researched in a larger or more varied sample.

The study results provide new risk factors for cervical cancer: uterine cervix, assisted vaginal delivery, episiotomy, and female genital mutilation. Any trauma to female genital organs is a predisposing factor to infection. Episiotomy, cervical laceration, and genital mutilation are major types of iatrogenic trauma. ${ }^{40}$ Infection with human papillomavirus is a fundamental risk factor for cervical cancer., ${ }^{2,3}$ The majority of women were episiotomized during delivery, and a higher number of pregnancies and multiparities were reported as risk factors for cervix uteri cancer. Women with these factors 
were about nine times more prone to cervical cancer than were women without these factors.Episiotomy is found to be one of risk factors for cervical cancer. ${ }^{42,43}$ If pregnant women diagnosed with cervical cancer are treated prior to delivery and go on to have an episiotomy, the cancer cells here will undergo metastasis. ${ }^{44}$

This pilot study showed that over two-thirds of women approached took the screening test. One explanation for this relatively high participation rate was probably the active information campaign. The screening facility was relatively easily accessed, and the examination was acceptable for most of the women. This finding was equal to that in Thailand, ${ }^{31}$ lower than that in the Philippines, and higher than that in Ghana. $^{27}$

The test is very simple and can be used effectively by nurses after 2 days of training. It is very cheap, costing about US\$5 per visit for a 3-year screening strategy.

This study is limited by its small sample size. A large sample size is needed to clarify the nature of the observed association between cervical cancer and risk factors in these results.

\section{Conclusion}

This pilot study showed that women in Khartoum State, Sudan, who had trauma to their cervix, such as uterine cervix laceration, assisted vaginal delivery, female genital mutilation, or episiotomy, are at an increased risk of cervical cancer. It also showed that VIA is a feasible and acceptable cervical cancer screening method in a primary health care setting.

The results showing trauma to the cervix as being a risk factor for cervical cancer point to the importance of safe delivery facilities and establishing guidelines and standard operation procedures for performing assisted vaginal delivery and episiotomy in obstetrics practice. Also, abandonment of female genital mutilation can have a great effect in decreasing the incidence of cervical cancer. Additional efforts are required in the training of birth attendants on safe delivery services and an increase in advocacy and community awareness about female genital mutilation risks. Further decisions on the introduction of cervical cancer screening in Sudan are critically needed.

\section{Disclosure}

The authors report no conflicts of interest in this work.

\section{References}

1. Carr KC, Sellors JW. Cervical cancer screening in low resource settings using visual inspection with acetic acid. J Midwifery Womens Health. 2004;49(4):329-337.
2. Castellsagué X, Bosch FX, Muñoz N, et al. International Agency for Research on Cancer Multicenter Cervical Cancer Study Group. Male circumcision, penile human papillomavirus infection, and cervical cancer in female partners. $N$ Engl J Med. 2002;346(15): $1105-1112$.

3. Castellsagué X, Bosch FX, Muñoz N. The male role in cervical cancer. Salud Publica Mex. 2003;45 Suppl 3:S345-S353.

4. Biswas LN, Manna B, Maiti PK, Sengupta S. Sexual risk factors for cervical cancer among rural Indian women: a case-control study. Int $J$ Epidemiol. 1997;26(3):491-495.

5. Muñoz N. Human papillomavirus and cancer: the epidemiological evidence. J Clin Virol. 2000;19:1-5.

6. Almonte M, Albero G, Molano M, et al. Risk factors for human papillomavirus exposure and co-factors for cervical cancer in Latin America and the Caribbean. Vaccine. 2008;26 Suppl 11:L16-L36.

7. Giuliano AR, Sedjo RL, Roe DJ, et al. Clearance of oncogenic human papillomavirus (HPV) infection: effect of smoking (United States). Cancer Causes Control. 2002:13(9):839-846.

8. Parikh S, Brennan P, Boffetta P. Meta-analysis of social inequality and the risk of cervical cancer. Int J Cancer. 2003;105:687-691.

9. Zhang J, Thomas A, Leybovich E. Vaginal douching and adverse health effects: a meta-analysis. Am J Public Health.1997;87:1207-1211.

10. Auvert B, Sobngwi-Tambekou J, Cutler E, et al. Effect of male circumcision on the prevalence of high-risk human papillomavirus in young men: results of a randomized controlled trial conducted in Orange Farm, South Africa. J Infect Dis. 2009;199(1):14-19.

11. Brinton L, Reeves W, Brenes M, et al. Parity as a risk factor for cervical cancer. Am J Epidemiol. 1989;130(3):486-496.

12. Rabelo-Santos SH, Zeferino L, Villa LL, et al. Human papillomavirus prevalence among women with cervical intraepithelial neoplasia III and invasive cervical cancer from Goiânia, Brazil. Memórias do Instituto Oswaldo Cruz. 2003;98:181-184.

13. Schiff M, Miller J, Masuk M, et al. Contraceptive and reproductive risk factors for cervical intraepithelial neoplasia in American Indian women. Int J Epidemiol. 2000;29:983-990.

14. Kanato M, Saranrittichai K. Early experience of sexual intercourse: a risk factor for cervical cancer requiring specific intervention for teenagers. Asian Pac J Cancer Prev. 2006;7(1):151-153.

15. Duncan ME, Pelzer A, Tibaux G, Mehari L. Is cervical cancer in Ethiopian women the result of a sexually transmitted disease? Int Surg. 1993;78(2):134-140.

16. Shields TS, Brinton LA, Burk RD, et al. A case-control study of risk factors for invasive cervical cancer among US women exposed to oncogenic types of human papillomavirus. Cancer Epidemiol Biomarkers Prev. 2004;13(10):1574-1582.

17. The New York Times Company. Cervical cancer. http://adam.about. com/reports/000046_2.htm. Accessed February 3, 2011.

18. Celentano D, Klassen A, Weisman C, Rosenshein N. The role of contraceptive use in cervical cancer: The Maryland Cervical Cancer Case-Control Study. Am J Epidemiol. 1987;126:592-604.

19. Menczer J. The low incidence of cervical cancer in Jewish women. Isr Med Assoc J. 2003;5(2):120-123.

20. Blumenthal PD, Gaffikin L, Deganus S, et al. Cervical cancer prevention: safety, acceptability and feasibility of single-visit approach in Accra, Ghana. Am J Obstet Gynecol. 2007;196:407-409.

21. Sankaranarayanan R, Ramani S, Wesley. A Practical Manual on Visual Screening for Cervical Neoplasia. Lyon, France: IARC; 2003.

22. Wright TC Jr. Chapter 10: cervical cancer screening using visualization techniques. J Natl Cancer Inst. 2003;31:66-71.

23. Wright TC Jr, Menton M, Myrtle JF, et al. Visualization techniques (colposcopy, direct visual inspection, and spectroscopic and other visual methods). Summary of Task Force 7. Acta Cytol. 2002;46(5): 793-800.

24. Arbyn M, Sankaranarayanan R, Muwonge R, et al. Pooled analysis of the accuracy of five cervical cancer screening tests assessed in eleven studies in Africa and India. Int $J$ Cancer. 2008;123(1): 153-160. 
25. Ogunbowale T, Lawoyin TO. Cervical cancer risk factors and predictors of cervical dysplasia among women in south-west Nigeria. Aust J Rural Health. 2008;16(6):338-342.

26. Soler ME, Blumenthal PD, Gaffikin L, et al. Visual inspection with acetic acid for cervical cancer screening: test qualities in a primary-care setting. Lancet. 1999;353:869-873.

27. Blumenthal PD, Gaffikin L, Deganus S, et al. Cervical cancer prevention: safety, acceptability, and feasibility of a single-visit approach in Accra, Ghana. Am J Obstet Gynecol. 2007;196:407-409.

28. Bhatla N, Gulati A, Mathur SR, et al. Evaluation of cervical screening in rural North India. Int J Gynaecol Obstet. 2009;105(2):145-149.

29. Sarian LO, Derchain SF, Naud P, et al. Evaluation of visual inspection with acetic acid (VIA), Lugol's iodine (VILI), cervical cytology and HPV testing as cervical screening tools in Latin America. This report refers to partial results from the LAMS (Latin AMerican Screening) study. J Med Screen. 2005;12(3):142-149.

30. Goldie SJ, Gaffikin L, Goldhaber-Fiebert JD, et al. Cost effectiveness of cervical cancer screening in five developing countries. NEngl JMed. 2005;353:2158-2168.

31. Gaffikin L, Lauterbach M, Emerson M. Safety, acceptability, and feasibility of a single visit approach to cervical cancer prevention: results from demonstration project in rural Thailand. http://www.jhpiego.org/scripts/ pubs/product_detail.asp?product_id=572. Accessed February 3, 2011.

32. Neumann G, Rasmussen KL, Petersen LK. Cervical adenosquamous carcinoma: tumor implantation in an episiotomy scar. Obstet Gynecol. 2007;110(2 Pt 2):467-469.

33. Baloglu A, Uysal D, Aslan N, Yigit S. Advanced stage of cervical carcinoma undiagnosed during antenatal period in term pregnancy and concomitant metastasis on episiotomy scar during delivery: a case report and review of the literature. Int J Gynecol Cancer. 2007;17(5): 1155-1159.

34. Bader AA, Bjelic-Radisic V, Tamussino KF, et al. Recurrence in a Schuchardt incision after Schauta-Amreich radical vaginal hysterectomy for cervical cancer. Int J Gynecol Cancer. 2006;16(3):1479-1481.
35. Cliby WA, Dodson MK, Podratz KC. Cervical cancer complicated by pregnancy: episiotomy site recurrences following vaginal delivery. Obstet Gynecol. 1994;84(2):179-182.

36. Khalil AM, Khatib RA, Mufarrij AA, et al. Squamous cell carcinoma of the cervix implanting in the episiotomy site. Gynecol Oncol. 1993;51(3): 408-410.

37. Gordon AN, Jensen R, Jones HW 3rd. Squamous carcinoma of the cervix complicating pregnancy: recurrence in episiotomy after vaginal delivery. Obstet Gynecol. 1989;73(5 Pt 2):850-852.

38. Munoz N, Franceschi S, Bosetti C, et al. Role of parity and human papillomavirus in cervical cancer: the IARC multicentric case-control study. Lancet. 2002;359:1093-1101.

39. Li N, Dai M. Relationship between multiple infections of human papillomavirus and cervical neoplasia among Chinese women in urban areas. Zhonghua Yu Fang Yi Xue Za Zhi. 2010 May;44(5):423-6.

40. Brady M. Female genital mutilation: complications and risk of HIV transmission. AIDS Patient Care STDs. 1999;13(12):709-716.

41. Punyaratabandhu P, Supanvanich S, Tirapat C, Podhipak A. Epidemiologic study of risk factors in cancer of the cervix uteri in Thai women. J Med Assoc Thai. 1982;65(5):231-239.

42. Goldman NA, Goldberg GL. Late recurrence of squamous cell cervical cancer in an episiotomy site after vaginal delivery. Obstet Gynecol. 2003;101(5 Pt 2):1127-1129.

43. Cliby WA, Dodson MK, Podratz KC. Cervical cancer complicated by pregnancy: episiotomy site recurrences following vaginal delivery. Obstet Gynecol. 1994;84(2):179-182.

44. Baloglu A, Uysal D, Aslan N, Yigit S. Advanced stage of cervical carcinoma undiagnosed during antenatal period in term pregnancy and concomitant metastasis on episiotomy scar during delivery: a case report and review of the literature. Int $J$ Gynecol Cancer. 2007;17(5):1155-1159.
International Journal of Women's Health

\section{Publish your work in this journal}

The International Journal of Women's Health is an international, peerreviewed open-access journal publishing original research, reports, reviews and commentaries on all aspects of women's healthcare including gynecology, obstetrics, and breast cancer. Subject areas include: Chronic conditions (migraine headaches, arthritis, osteoporosis);

\section{Dovepress}

Endocrine and autoimmune syndromes; Sexual and reproductive health; Psychological and psychosocial conditions. The manuscript management system is completely online and includes a very quick and fair peer-review system. Visit http://www.dovepress.com/ testimonials.php to read real quotes from published authors. 